Research Journal of Biological Sciences 5 (1): 116-117, 2010

ISSN: $1815-8846$

(C) Medwell Journals, 2010

\title{
Assessment of Soil in Criteria Indices for Desertification with IMDPA Model and GIS (Case Study: Mazayijan Iran)
}

\author{
Reza Zakerinejad and Masoud Masoudi \\ Department of Desert Zones Management, Agricultural College, University of Shiraz, Iran
}

\begin{abstract}
Desertification is the consequence of a set of important processes which are active in arid and semiarid environments where water is the main limiting factor of land use performance in ecosystem. The desertification phenomenon with all the problems it cause, most great effect will remain in soil, so by assessing soil variation, the researchers can reach the intensity of desertification. For this purpose IMDP (Iranian Model of Desertification Potential Assessment) a methodology that prepared by natural resources college, Tehran university was used to determine map of desertification emphasize in soil criteria in mazayjan region as arid that including EC, soil deep, soil texture and the amount of sub soil gravel are recommended in order to assess the intensity of desertification mazayjan basin. Subhumid area of Iran. Score of indices were recorded in different work units. At last using the following formula $\mathrm{SI}_{\mathrm{i}}=\sqrt[4]{\mathrm{x}_{1} \cdot \mathrm{x}_{2} \cdot \mathrm{x}_{3}}$. Final score of soil character was determined in the study area based on IMDPA.
\end{abstract}

Key words: Desertification, IMDPA, GIS, phenomenon, determine, scoring

\section{INTRODUCTION}

Desertifications a phenomenon that happens in any reason make it expand in many parts of world. More that 135 million ha of area in world are affected desertification. This process has a high rate in arid semiarid countries such as Iran.

In this area desertification cause soil lost, make a transient basis that is not suitable for socio-economic activities specially agriculture and irrigation. Desertification comes about by a complex interaction between the natural environment and human activities. The cause may vary from region to region on account of economic conditions, population pressure, agricultural practices and politics.

A human activity that destroys surface vegetation, degrades soil structure and fertility, impedes water infiltration and causes soil drying promotes desertification. This is especially true for the fragile transition zone between arid and semiarid land where human activity has stretched the ecosystem to its limit causing expansion of deserts.

Many studies have been done to introduce land degradation assessment methods i.e., FAO/UNEP (1984, 2001). Turkministan model, Glasod, Medalus, LADA, etc. Ladsia (2002) studies desertification of Barry in Italy with MEDALUS model in this research indices such as soil, climatic, vegetation, land use, mangment quality and anthropogenic factor were evaluated. Ekhtesasi and Mohajeri (1995) developed the ICD (Iranian Classification Deserts) model for the classification of Iranian deserts. One of the advantages of the ICD model is its capability to identify the type of desert environment such as natural and anthropogenic. Hence, to have a model with national application and adaptable it is necessary to design a effective indications in desertification.

\section{MATERIALS AND METHODS}

Study area: Mazayjan plain is located in the zarindasht, Southern Iran $\left(54^{\circ} 34^{\prime} 59-54^{\circ} 44^{\prime} 83 \mathrm{E}\right.$ and $\left.27^{\circ} 59^{\prime} 20-28^{\circ} 05^{\prime} 1 \propto \mathrm{N}\right)$ has a maximum altitude of $1,092 \mathrm{~m}$ and comprises one geomorphologic main units is a plain unit with 20 facieses (Fig. 1).

The annual rainfall is $234 \mathrm{~mm}$ with a high interannual variability. In this desert environment, the hottest month is July and the coldest is January with mean monthly maximum and minimum temperatures of 31.34 and $17.6^{\circ} \mathrm{C}$, respectively.

In order to evaluate soil role in desertification, a part of kol basin in Fars provinces was chosen as study area.

Methodology: Among different effective indices of soil indicator in desertification, four indices including soil deep, EC soil, texture soil and fragment were chosen. Table 1 shows the indices and scoring. As it is shown in Table 1, there are four classes for representation of desertification severity based on soil indices effects.

Corresponding Author: Department of Desert Region Management, Agriculture College, University of Shiraz, Shiraz, Iran 


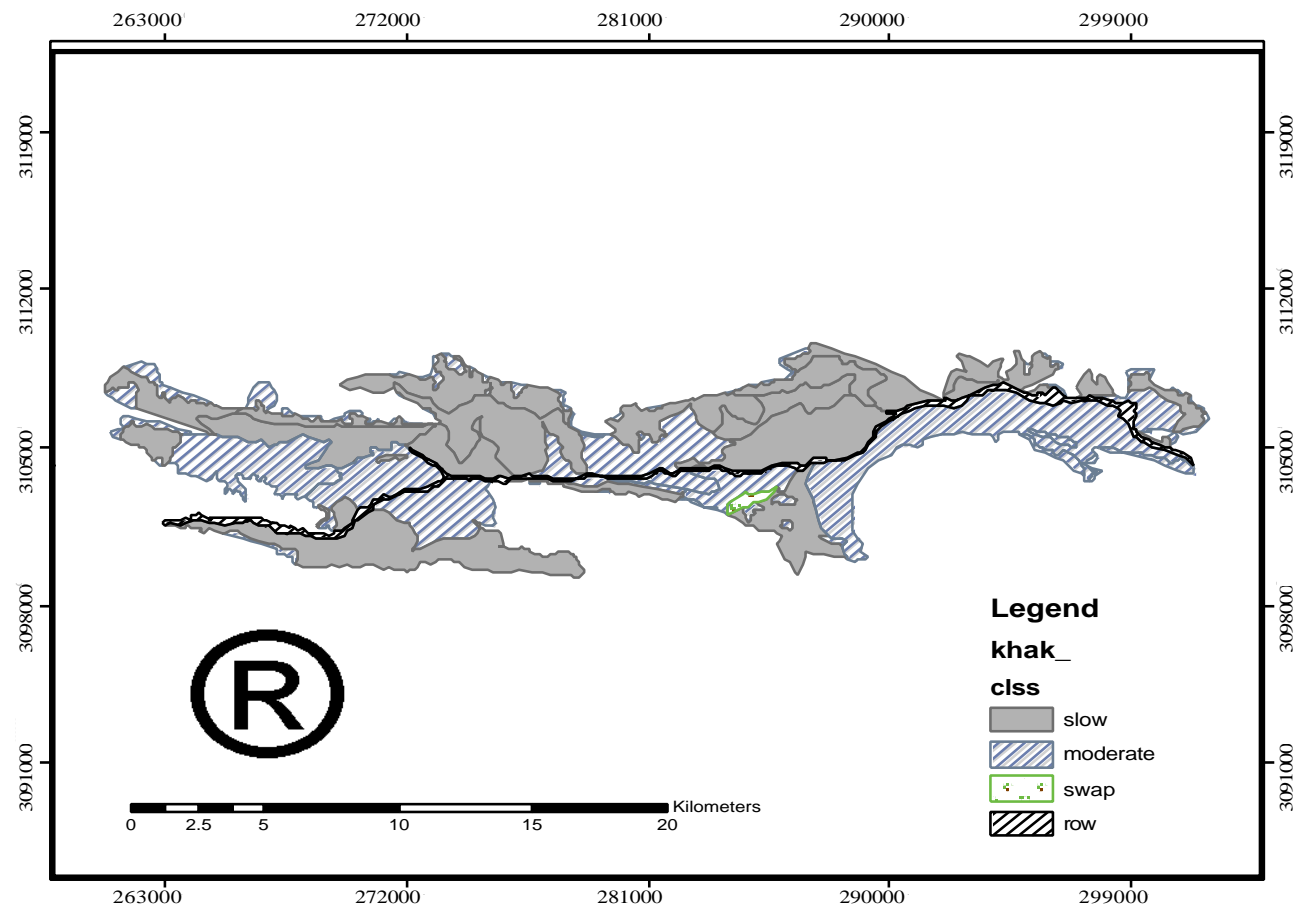

Fig. 1: Map of current desertification status caused by soil

Table 1: Classes and values of various parameters used for assessment of soil quality

\begin{tabular}{lllll} 
Index & $\begin{array}{l}3.6-4 \\
\text { (Strongly) }\end{array}$ & $\begin{array}{l}2.6-3.5 \\
(\text { Severe) }\end{array}$ & $\begin{array}{l}1.6-2.5 \\
\text { (Moderate) }\end{array}$ & $\begin{array}{l}0-1.5 \\
\text { (Low) }\end{array}$ \\
\hline EC & $>16$ & $8-16$ & $5-8$ & $<5$ \\
$\begin{array}{l}\text { Deep }(\mathrm{cm}) \\
\text { Texture }\end{array}$ & $<20$ & $20-50$ & $50-80$ & $>80$ \\
& $\mathrm{~S}$ & $\mathrm{Si}, \mathrm{C}, \mathrm{SiC}$ & $\mathrm{SiCL}, \mathrm{SiL}$, & $\mathrm{SCL}$, \\
$\begin{array}{l}\text { Amount of subsoil } \\
\text { gravel (\%) }\end{array}$ & $>75$ & $35-75$ & $\mathrm{SC}$ & $\mathrm{SL}, \mathrm{LS}, \mathrm{CL}$ \\
& & & $15-35$ & $<15$ \\
\end{tabular}

Score $0-1.5$ is representative of class low of desertification that is if any index lies between $0-1.5$, therefore its influence on desertification is low, 1.6-2.5, 2.6-3.5 and 3.6-4 are the scores to show moderate, severe and strongly severe classes of vegetation induced desertification. In this method, it is possible to provide a desertification potential map considering each index score using GIS technology. The final score of desertification potential caused soil obtains using geometric mean method by means of the following formula:

$$
\mathrm{SI}_{\mathrm{i}}=\sqrt[4]{\mathrm{SE}_{1} \times \mathrm{SD}_{2} \times \mathrm{XT}_{3} \times \mathrm{XS}_{4}}
$$

\section{RESULTS AND DISCUSSION}

The map of current desertification status caused soil, prepared according to final score of soil indicator (Fig. 1). Table 2 shows the surface areas of each desertification classes by soil that indicates 53.63 and 42.05 of the study area are considered as low, moderate desertification intensity classes, respectively.
Table 2: Extent of desertification classes in Mazayijan basin

\begin{tabular}{lcc} 
Desertification intensity & Area (ha) & Area (\%) \\
Low & 10727.10 & 53.63 \\
Moderate & 8411.97 & 42.05 \\
\hline
\end{tabular}

\section{CONCLUSION}

After scoring soil character desertification intensity map of soil character including four low, medium intensive and very intensive classes was prepared the map showed that 53.63 and $42.05 \%$ of the study area considered as low and medium desertification intensity, respectively.

\section{REFERENCES}

Ekhtesasi, M.R. and S. Mohajeri, 1995. Iranian classification of desertification method. Proceedings of the 2nd National Conference of Desertification and Combating Desertification Methods, Kerman, Iran.

FAO/UNEP, 1984. Provisional Methodology for Assessment and Mapping of Desertification. Food and Agriculture Organization of the United Nations, United Nations Environmental Programme, Rome, Italy, pp: 73 .

FAO/UNEP, 2001. Land Degradation Assessment in Dry Land LADA. UNEP, USA., pp: 67.

Ladsia, G., 2002. Characterization of areas sensitive to desertification in Southern Italy. Proceedings of 2nd International Conference on New Trend in Water and Environmental Engineering for Safety and Life, June 24-28, Italy, pp: 118-118. 